tions very similar to those of the corresponding normal parameters. The fact that British methods 'work' is due to the prevalence in Nature of distributions similar to the Gaussian rather than to any peculiar virtue in the methods thernselves. I am writing this in the hope that some statistician of international repute will be tempted to treat the matter fully in some publication such as NATuRE available to statisticians of all countries.

\section{H. J. BuOHaNaN-Wollaston.}

Fisheries Laboratory, Lowestoft.

\section{Philosophy and Modern Science}

I Do not know whether in a brief compass I can say anything useful in regard to Dr. Jeffreys's letter in Nature of July 20. Yet it seems a pity that the cardinal psychological distinction upon which I was laying stress ${ }^{1}$ should be obscured by mere misapprehension and confusion.

I thought I had made sufficiently clear what I meant by the term sensum, namely, that which is sensed or perceived, in contradistinction to the sensing or perceiving. I was not in the least concerned with Russell's theory of sense-data, or as to whether most of what Russell called sense-data are or are not perceived. All I desired to insist upon was that sensing or perceiving is not identical with that which is thereby sensed or perceived. Dr. Jeffreys now tells us that what he means by sensations are such things as various patches of different shapes and colours of which he is aware when his eyes are open, and which disappear when his eyes are closed. Precisely; he is using the term sensation, as I suspected, for that which is sensed, and is ignoring, although all the while assuming (in speaking, namely, of being aware), a process of sensing.

He now maintains that sensations, so understood, seem to be immediate and not to be the result of activity on the part of the conscious subject. With the latter part of this statement I thoroughly concur; but when I am further told that sensations, or sensa, "just happen", I feel bewildered. Surely, patches of various shapes and colours do not "happen"; they simply are; what "happens" is the state or condition of being aware of them. The latter is the mental act; and it is, of course, wholly different from a bodily activity, such as that of "opening my eyes". Whether there be any process rightly describable as "merely having a sensation" is more than doubtful ; but most certainly if there is, it is a case of mental activity. Not even the crudest, the most indefinite, awareness of a sensuous content is conceivable which does not involve the functions of discriminating and comparing, which functions, as the result of development, ultimately assume the highly evolved form of mental activity we call thinking.

Again, the statement in my letter that a concept, psychologically considered, is a way in which universals are cognised presupposes by no manner of means the existence of universals. We cognise numerous entities-numbers, for example-which are not existents. Indeed, the point $I$ was urging was that an individual existent, such as the planet Neptune, is obviously neither a universal nor a concept. Dr. Jeffreys now informs us, "It is only when many observations are available that we can form the idea of a single body moving in a definite way ; generalisa- tion has already been applied in thinking of Neptune at all". Quite true; but what has that to do with the matter? Generalising is, in fact, involved in every act of mature perception, in my perception, for example, of the table at present in front of me; but it does not follow that the object perceived is, on that account, itself a generalisation. Dr. Jeffreys further informs us that what he calls a percept is substantially what Pearson called a construct. Well, I suppose a writer is at liberty to use a term in any sense he chooses. But it is, to say the least, unfortunate when a term with a well-recognised connotation is employed in a manner altogether contrary to its ordinary meaning. Even in popular language, the term 'concept', according to the "Oxford Dictionary", signifies "idea of a class of objects, general notion"'. The "idea of a single body moving in a definite way" is doubtless an idea of a highly complex object; but it is not, as such, an idea of a class of objects.

\section{Cranmer Road, Cambridge. July 22.}

${ }^{1}$ Nature, 135, 1035, June 22, 1935.

\section{G. DAwES HiCks.}

\section{The Carr and Price Reaction of the Fatty Acids of Cod Liver Oil after Vigorous Saponification}

IT has been demonstrated ${ }^{1-5}$ that prolonged and vigorous saponification of the mixed free acids of fish-liver oils causes remarkable changes in their chemical structure and in the absorption in the ultra-violet. When saponifying the acids of cod liver oil in this way, I observed a remarkable change in the Carr and Price reaction of these acids.

Cod liver oil was saponified for 10 minutes with ethyl alcoholic potash, and the unsaponifiable fraction extracted with ether. The fatty acids were distilled (at $0.2 \mathrm{~mm}$.). They were pale yellow in colour and gave with antimony trichloride in chloroform only a yellow colour. The acids were saponified for six hours in nitrogen under reflux with an excess of amyl alcoholic potash. (The amyl alcohol was previously distilled over potash.)

The regenerated acids gave with the Carr and Price reagent a relatively strong and rapidly decreasing violet colour with absorption at $600-620 \mathrm{~m} \mu$ and at $530-550 \mathrm{~m} \mu$. Measured with the Lovibond tintometer, these acids contained per c.c. 300 L.U. (Wolff) $=$ blue value 60 . The cod liver oil itself contained 70 L.U. (Wolff) = blue value 14 . The substance responsible for the reaction was purified by dissolving the acids in light petroleum and filtering through a Tswett column with activated aluminium oxide. A yellow coloured zone was visible at the top, unaltered even after washing with ethyl alcohol. The pigment was eluted with dilute ethyl alcoholic potash, regenerated by acidification and taken up in ether. After evaporation in vacuo, a pale brown. coloured semi-solid substance was obtained. Addition of light petroleum caused a yellow precipitate and removed soluble substances, which gave a reddish brown Carr and Price reaction. The precipitate was washed several times with light petroleum and dissolved in a small quantity of acetone or chloroform. So a colourless impurity which is insoluble in acetone and chloroform could be removed. After evaporation and drying in vacuo, a yellow amorphous powder was obtained. 